Бондаренко Игорь, кандидат технических наук E-mail: igor1957@mail.ru ORCID: 0000-0003-2925-3020

Тастанов Ербулат, доктор технических наук E-mail: tastanov_ea@mail.ru

Абдулвалиев Ринат, кандидат технических наук E-mail: rin-abd@mail.ru ORCID: 0000-0001-6747-6984

Темирова Сания, кандидат химических наук E-mail: stemirova@mail.ru ORCID: 0000-0003-3039-2546 $\mathrm{AO}$ «Институт металлургии и обогащения», г. Алматы, Казахстан

\title{
АКТУАЛЬНЫЕ ПРОБЛЕМЫ ТЕХНИЧЕСКИХ НАУК В КАЗАХСТАНЕ
}

Аннотация. В статье рассмотрены вопросы формирования компетентности менеджмента промышленных предприятий Казахстана и устоявшихся мифов, часто отрицательно влияющих на принятие правильных управленческих решений. Проблемь технических наук являются производными от уровня компетентности менеджмента производственных предприятий. В сложившейся системе производственных отношений ученые не имеют возможности влияния на принятие адекватных решений по технологическим вопросам, снижающим риски финансовых и репутационных потерь при реализачии технически необоснованных проектов. Предложен механизм подготовки квалифицированных инженерных и научных кадров. На примере Института металлургии и обогащения приводится модель создания международного консоричима и его дальнейшая научная деятельность, направленная на решение проблем повышения глубины переработки и комплексности использования сырья, снижения выбросов и переработки отходов производства.

Ключевые слова: компетентность руководства, техническое образование, автоматизация, компьютеризачия, бизнес-администрирование, глубина переработки, комплексность, экология.

Bondarenko Igor, Candidate of Technical Sciences E-mail: igor1957@mail.ru ORCID: 0000-0003-2925-3020

Tastanov Yerbulat, Doctor of Technical Sciences E-mail: tastanov_ea@mail.ru

Abdulvaliev Rinat, Candidate of Technical Sciences, E-mail: rin-abd@mail.ru ORCID: 0000-0001-6747-6984

Temirova Saniya, Candidate of Chemical sciences

E-mail: stemirova@mail.ru ORCID: 0000-0003-3039-2546 "Institute of Metallurgy and Ore Beneficiation" JSC, Almaty, Kazakhstan

\section{CHALLENGES OF TECHNICAL SCIENCES IN KAZAKHSTAN}

Abstract. The article raises the question of building up competence of industrial enterprises management in Kazakhstan and existing myths that often impede making reasonable administrative decisions. Most problems of engineering sciences stem from the competence level of management industrial enterprises. In the present system scientists do not have any opportunity 
to influence making adequate decisions on technological matters, reducing risks of financial and reputation losses that may arise during realization of technically ill-founded projects. The article offers a mechanism of preparing highly skilled engineering and scientific specialists. On the example of Institute of Metallurgy and Ore Benefication, the model given of creating international consortium and their further scientific activity, aimed at solving problems of increasing the level of processing and complexity of use of raw material, decreasing waste emission and wastes processing.

Keywords: competence of management, technical education, automation, computerization, business-administration, level of processing, complexity, ecology.

При рассмотрении актуальных, на наш взгляд, проблем науки, мы хотим сразу ограничиться областями точных технических наук, не включая науки гуманитарного направления. Вероятно, и у гуманитариев существуют подобные проблемы, но мы не компетентны в их обсуждении.

Технические науки являются важной составной частью процесса индустриального развития и их проблемы следует рассматривать взаимосвязано.

Современное промышленное предприятие - это сложный комплекс технологических, административных, финансовых, логистических и т.д. задач и их решений. Любое такое решение определяется компетентностью руководителя в данных вопросах и его предвидением будущих результатов воплощаемых сегодня решений.

Ключевым вопросом нормальной деятельности предприятий является компетентность первых руководителей, т.к. именно они должны принимать решения, определяющие судьбу вверенного им производственного объекта. Как известно, компетентность того или иного руководства (им может быть директор, Совет директоров, собрание учредителей и т.д.) определяется способностями, профильным образованием, техническим и жизненным опытом, карьерным прошлым и умением принимать решения на основе той информации, которая имеется на данный момент.

Соответствуют ли на сегодняшний день руководители предъявляемым к ним требованиям? Значительная их часть не в полной мере соответствует, по ряду причин. Прежде всего, в современном Казахстане сложно получить качественное техническое образование по тем технологиям, которые используются в стране. Мы считаем, что повсеместный переход высшего технического образования на «болонскую» систему был ошибкой. Что может иметь в своем багаже знаний бакалавр, например, в области металлургии, после четырех лет обучения? Выпускник Вуза по специальности «металлургия» должен иметь знания по технологиям производства более 60 металлов. В рамках учебной программы бакалавриата это невозможно освоить физически.

Большинство технических ВУЗов индустриально развитых стран (Германия, Япония, США) практикуют классическую систему подготовки инженерных кадров (с периодом обучения 5-6 лет) [1].

В советский период типичная карьера от молодого специалиста до первого руководителя включала множество ступеней: мастер смены, начальник отделения, начальник цеха, главный инженер, в ходе которых специалист приобретал знание различных технологий данного производства и их взаимосвязей, производственный и управленческий опыт.

Какова сегодняшняя ситуация? Молодые люди, не обладающие багажом необходимых знаний и профессиональных навыков, благодаря зарубежному, но 
непрофильному образованию и родственным связям становятся менеджерами управляющих компаний. При этом они не имеют глубоких понятий о технологических процессах, особенностях и отличиях предприятий, по которым им приходится принимать решения на уровне их ответственности.

Даже профильное зарубежное техническое образование не всегда является панацеей при решении кадровых вопросов из-за существенного различия технологий.

К сожалению, в нашем обществе, в том числе и среди руководителей высшего уровня предприятий, существует ряд устоявшихся мифов.

Миф первый - деньги решают все: можно за рубежом приобрести любую технологию, качественное оборудование и специалистов, которые могут совершить быструю технологическую модернизацию твоего предприятия. Во-первых, даже будучи классным специалистом на предприятиях в других странах мира, данные профессионалы, сталкиваясь с особенностями казахстанского сырья и технологий, могут оказаться совершенно неэффективными менеджерами. Особенно это проявляется в вопросах управлении проектами коммерциализации капиталоемких научных разработок $[2,3]$.

Во-вторых, оборудование для каждого производства достаточно индивидуально и часто требует соответствующих проектных расчетов, конструирования и изготовления. Часто непрофессиональное использование того или иного технологического оборудования и аппаратов приводит к нежелательным, а иногда и трагическим последствиям.

В-третьих, высокопрофессиональные зарубежные специалисты и менеджеры востребованы на своей родине и к нам приезжают не самые лучшие. Иностранные инжиниринговые фирмы не заинтересованы в продаже новейших технологических разработок и реализуют достаточно не новый товар, который может быть не самым инновационным, экономичным и экологичным. Руководствуясь сиюминутными финансовыми интересами, менеджмент промышленного предприятия игнорирует необходимость полноты и комплексности переработки минерального сырья, в то время как не имеется долгосрочных научно обоснованных прогнозов о перспективе применения тех или иных химических элементов в прорывных технологиях.

Миф второй - передовые достижения в области автоматизации и компьютеризации совершат коренной прорыв в производственном процессе. Конечно, достаточно высокий уровень автоматизации и компьютеризации способствует определенному росту производительности труда и производства, но это только при условии, что сами производственные процессы налажены и требуется определенная коррекция, чтобы все работало идеально. В условиях, когда даже не соблюдаются проектные технологические параметры, все эти мероприятия мало эффективны.

Миф третий - менеджеры по бизнес-администрированию могут решать вопросы, касающиеся инженерной и инновационной деятельности профильных специалистов на предприятии. Принято считать, что они являются универсальными менеджерами, которые способны принимать адекватные решения в любой сфере. Нужно понимать, что любой бизнес-план - это некая идеализированная модель финансирования и ожидаемых финансовых выгод от реализации проекта, учитывающая далеко не все технологические риски. Показательным примером такого непрофессионального и непродуманного подхода является, например, проект Бадамшинского никелевого завода [4]. Внедрение любой новой технологии, оборудования, инновационного продукта проходит длительный и затратный путь научных лабораторных исследований и опытных испытаний, конструирования и проектирования. Причем, ошибки, просчеты, а иногда и фальсификация результатов, могут проявиться на любой стадии проекта. Цена вопроса известна - простаивающее или 
неработающее на полную проектную мощность новое предприятие, бесполезно потраченные финансы, недополученные налоги и необеспеченность рабочими местами. В качестве примеров можно привести такие предприятия, как северо-казахстанский «Биохим» и карагандинский «Силициум», цинковый завод в Балхаше и цех №4 в Актобе $[5,6]$ и другие неудачные проекты. К этой же категории мифа относится то, что кредитные офицеры казахстанских банков в состоянии разобраться с нюансами технологических проектов и дать им объективную оценку.

Миф четвертый - диверсификация экономики предприятия снижает риски экономической нестабильности и повышает его финансовую устойчивость. Большинство проектов в Казахстане начинается с чистого листа, без опыта ранее успешно реализованных проектов и без четкой долговременной стратегии на перспективу. Не доводя до конца один проект, начинаем новый. При таком подходе говорить о финансовой устойчивости и эффективности потраченных средств не приходится.

Миф пятый. Он более распространен в среде казахстанского чиновничества и бюрократии. Создавая необходимые условия (административные, снятие неких барьеров и налогов, строительство бизнес-инкубаторов, технопарков и т.д.), можно быстро повысить инновационную активность населения и производственных предприятий. Без грамотных специалистов итог известен: несостоятельные венчурные фонды, технопарки и бизнесинкубаторы, существующие исключительно на государственные субсидии.

Миф шестой - персонал казахстанских предприятий нацелен на повышение производственных показателей без соответствующей финансовой мотивации вложенного интеллектуального труда. Вместо этого имеет место необдуманное копирование зарубежных технологий работы с персоналом, выражающееся, например, в требовании носить элементы одежды определенного цвета, являющегося фирменным знаком компании, что должно якобы поддерживать корпоративную солидарность сотрудников.

Исходя из современной ситуации с компетентностью менеджмента производственных предприятий Казахстана, возникает вопрос о влиянии и месте казахстанского образования и науки. Руководство предприятий должно самокритично осознать сложившийся у них уровень компетентности и принимать меры по привлечению ученых для участия в принятии адекватных решений по технологическим вопросам. Ответ прост - повышать компетентность на всех звеньях руководства предприятиями. Для этого необходимо создать институт компетентных советников и консультантов, в качестве которых должны быть привлечены казахстанские ученые и специалисты, реально работающие в соответствующей области знаний.

Условно говоря, следует рационально использовать ранее накопленный опыт для снижения рисков принятия некомпетентных решений. Уровень профессиональных знаний позволит минимизировать и нивелировать потери будущих проектов от некомпетентных решений. Финансирование деятельности таких ученых и научных коллективов сполна окупит потери от некомпетентных проектов [7]. Однако это временная мера. В перспективе нужно взращивать компетентные кадры из числа перспективных молодых специалистов. В Казахстане в технических университетах на высших стадиях подготовки обучается достаточно большое количество магистрантов и докторантов философии. Как правило, их будущие диссертационные работы связаны не с конкретными потребностями в инновациях промышленных предприятий, а с достаточно отвлеченными от реальности темами. Для формирования тематики будущих диссертационных работ предлагается в первом семестре обучения в магистратуре или докторантуре командировать соискателей на промышленные предприятия Казахстана с целью прохождения научно-производственной стажировки в их 
аналитических и исследовательских подразделениях. По итогам стажировки Технический совет предприятия заслушивает отчет о практике, включающий предложения стажера по выбору темы научной работы, способствующей в перспективе улучшению деятельности предприятия. Одобряется тема диссертационной работы, назначается куратор от предприятия, который обеспечивает его необходимой материалами и технической информацией для подготовки диссертационной работы. Одобренная на предприятии тема утверждается Ученым советом ВУЗа. После проведения исследований по теме диссертации ее предзащита проходит на Техническом совете предприятия и соискатель получает одну из рецензий по работе от предприятия. Формально и сейчас требуется рецензия от предприятия, но в сегодняшних условиях она обычно представляет собой предложения по использованию результатов исследований в учебном процессе или при подготовке учебной и научной литературы, т.е. конкретного технологического воплощения результатов исследований нет.

По результатам защиты диссертационной работы дипломированный специалист должен иметь возможность получить работу в подразделении инновационного развития компании.

Механизм взаимосвязи молодых специалистов и предприятий должно выработать Министерство образования и науки и, если потребуется, сформировать необходимую законодательную базу в виде законов или Постановлений Правительства. Источником финансирования данной программы подготовки высококвалифицированных специалистов должны выступить сами промышленные предприятия в рамках обязательного отчисления $1 \%$ совокупного годового дохода на обучение персонала.

Мы все постоянно призываем к дальнейшей индустриализации Казахстана, внедрению последних достижений науки и техники. Но для осуществления правильного и планомерного продвижения вперед нам объективно и критично нужно оценить сегодняшнее наше состояние, в т. ч. и в горно-металлургическом комплексе страны. На сегодняшних казахстанских предприятиях существуют базовые проблемы повышения глубины переработки и комплексности использования сырья, снижения выбросов и переработки отходов производства, вопросы экологии [8]. Контролирующие функции МИР РК кардинально не могут изменить положение, нужно не только зафиксировать точки «нулевого» отсчета, но и разработать совместно с предприятиями долгосрочные программы улучшения ситуации, в.т.ч. и с внедрением инновационных технологий. Министерством индустрии должны быть разработаны общегосударственные программы развития и подготовлены законодательные основы для планомерного и поступательного движения вперед. И именно в этом направлении необходимо привлечение казахстанских ученых в экспертные группы по оценке существующего положения и разработке технологических решений по его улучшению. Таким образом, нужно налаживать связь предприятий и науки, способствовать росту компетентности кадров молодых ученых. Нужно отметить, что компетентность нужно повышать и в научной среде путем трансферта последних инновационных достижений в данных областях. Как этого добиться? [9]. Несмотря на то, что за последние 10 лет наш Институт приобрел современное высокоэффективное аналитическое и исследовательское оборудование, пригласил на работу перспективные молодые кадры существует проблема специализации только как исследовательской организации. Современные зарубежные исследовательские центры являются инжиниринговыми фирмами, включающими не только исследовательскую, но и инжиниринговую часть, которая может включать и поставки оборудования, авторский надзор и сдачу производственного объекта «под ключ». Практически большинство из них 
работают в тесном контакте друг с другом в рамках международного сотрудничества и с привлечением лучших мировых специалистов по направлениям реализуемых проектов. Наш институт не может быть расширен до уровня инжиниринговой компании, в т.ч. и по причине недофинансирования научных исследований и разработок.

Финансовая поддержка МОН РК в виде грантового или программно-целевого финансирования не обеспечивает процесса развития науки, отвечающего уровню потребностей промышленных предприятий. Поэтому для продвижения проекта от стадии научных исследований к стадиям инжиниринга и проектирования нам необходима коллаборация с крупными зарубежными инжиниринговыми компаниями, имеющими международный авторитет, компетентных специалистов в разных областях знаний, уникальное оборудование и опыт в подготовке финансовых ТЭО, признаваемых международными банками. Такими партнерскими компаниями могли бы стать финский Оутотек, англо-американский Минтек, ведущие китайские компании. Формы юридического объединения могут быть самыми разнообразными. Данный проект мог бы стать пилотным для МОН РК. Подобный алгоритм действий решает такие проблемы, как:

- научный коллектив международного уровня и подготовка молодых научных кадров на перспективу;

- выполнение исследований на требуемом международном уровне;

- постепенный и безболезненный отход от системы государственного финансирования по механизму грантового и программно-целевого финансирования к коммерциализации работы;

- формирование казахстанского и международного имиджа;

Одним из основных будущих работодателей международного консорциума выступит МИР РК, под руководством которого должны разрабатываться программы развития и улучшения деятельности предприятий. Министерство на сегодняшний день реально не влияет на процессы улучшения производственной деятельности предприятий и роста инноваций на них. Разработка и создание законодательных документов, обеспечивающих соответствие деятельности предприятий требованиям ресурсосбережения и экологичности, реально позволит улучшить их производственную деятельность.

На сегодняшний день промышленные предприятия-недропользователи в Казахстане в обязательном порядке должны 1 \% от совокупного годового дохода отчислять на научные исследования. Эффективность данных отчислений слабо контролируемая.

Другим источником финансирования научных исследований могут стать штрафные санкции. Выплаты за нарушение экологических и технологических норм, существующих на предприятиях развитых стран, значительны и сопоставимы с прибылью данных предприятий. Почему подобный механизм регулирования не использовать в Казахстане? Причем выплаты поступающие в бюджет, дожны быть целенаправленно использованы для устранения вышеназванных проблем. Одним из направлений финансирования должна стать разработка научных проектов по улучшению работы конкретных предприятий с участием в их разработке казахстанских ученых, в том числе и предлагаемой международной исследовательской группы. Предлагаемый алгоритм финансирования и развития технических наук является более действенным и плодотворным, чем существующая система грантового и программно-целевого финансирования и способствует тесной ассоциации науки и производства.

Вполне возможно, что в данной статье мы предлагаем не единственно возможные пути решения проблем казахстанского производства, науки и образования, но, во всяком случае, затрагиваем существующие на сегодня проблемы. Дискуссии и последующий 
правильно выбранный алгоритм решения существующих проблем является целью данной статьи.

\section{СПИСОК ЛИТЕРАТУРНЫХ ИСТОЧНИКОВ}

1. Сериков Э.А. О национальной модели образования Казахстана и болонском процессе // Вестник Алматинского университета энергетики и связи. -2010.- № 3/1.

2. Bagdaulet Kenzhaliyev, Bolysbek Utelbayev, Essen Suleimenov. Innovations in fundamental studies for education // European Scientific Journal, June 2015. /SPECIAL/ edition ISSN: 1857 - 7881 (Print) e - ISSN 1857- 7431 220.

3. Кенжалиев О.Б., Салыкова Л.Н., Ильмалиев Ж.Б., Садыкова Т.С. Обзор проблем в управлении проектами коммерциализации капиталоемких научных разработок // Комплексное использование минерального сырья». - 2018. - № 3. - С. 101-108. DOI: 10.31643/2018/6445.23

4. «БТА Банк» отсуживает у завода в Бадамше более 17 миллиардов. Газета «Диапазон» от 5 ноября 2017 г.

5. М. Козачков. Брать-2. Газета «Время» от 17 января 2018 г.

6. Суперсовременный цинковый завод корпорации «Казахмыс» остановлен. Today.kz. от 9 июня 2009.

7. Осипов Г.В., Стриханов М.Н., Шереги Ф.Э. Мотивация заработать деньги с помощью НИР/ НИОКР // В сб. «Взаимодействие науки и производства: социологический анализ». М.: ЦСП и M, 2014. - C. 59-72.

8. Д. Муканов. Казахстан на пути ускоренной экономической, социальной и политической модернизации. Промышленность Казахстана. - 2005. - 1(28). - С. 4-11.

9. K. G. Kassymova, Competence and its implications. Materials of International Practical Internet Conference "Challenges of Science" 2018. https://doi.org/10.31643/2018.063

Технические науки в Казахстане
Материалы Международной практической интернет-конференции «Актуальные Проблемы Науки» 